\title{
Efficient Gas Adsorption Using Superamphiphobic Porous Monoliths as the Under-liquid Gas- Conductive Circuits
}

Min Wen ${ }^{l a}$, Cheng Peng ${ }^{l b}$, Ming Yao ${ }^{l a}$, Chao Wang ${ }^{a}$, Tingzhen Ming ${ }^{c}$, Biaoling Peng ${ }^{d}$, Fuzhi Huang $^{a}$, Jie Zhong ${ }^{*}$, Yi-Bing Cheng ${ }^{a}$, Qi Zhang ${ }^{* a e}$

a. State Key Laboratory of Advanced Technology for Materials Synthesis and Processing, School of Materials Science and Engineering, Wuhan University of Technology, Wuhan, 430070, China.

b. Department of Plastic Surgery, the Third Xiangya Hospital, Central South University, Changsha 410083, China.

c. School of Civil Engineering and Architecture, Wuhan University of Technology, Wuhan 430070, China.

d. Center on Nanoenergy Research, School of Physical Science \&Technology, Guangxi University, Nanning 530004, China.

e. School of Aerospace, Transport and Manufacturing, Cranfield University, Cranfield, Bedfordshire, MK43 0AL, United Kingdom

1 Those authors contribute equally to this work

*Corresponding author, email: jie.zhong@whut.edu.cn (Jie Zhong); q.zhang@cranfield.ac.uk (Qi Zhang)

KEYWORDS: Superamphiphobic, porous monolith, gas conductor, gas adsorption, blood oxygenation 
ABSTRACT: The gas-liquid membrane contactor forms a gas-solid-liquid interface and has a high potential for the applications in gas adsorption, catalysis, energy exchange and so on. Porous superhydrophobic membranes show a great gas separation/adsorption ability. However, the complicated device architecture and the durability issue are normally concerned especially for the continuous circulation of gas and liquid. In this work, we present a free-standing gas-conductive circuit simply formed by connecting the porous superamphiphobic monoliths (SAPM) to achieve an efficient under-liquid gas adsorption. The porous worm-like SAPM is prepared with lowtemperature expandable graphite (LTEG) and polyvinylidenefluoride (PVDF), exhibiting superamphiphobicity and superaerophilicity after fluoridation. The as-made SAPM circuits can be used as a reliable gas conductor under numerous liquids, such as water, alkaline, acidic and oily solutions. In this work, the $\mathrm{CO}_{2}$ adsorption capacities of the SAPM circuits are evaluated under $\mathrm{NaOH}$ and methyldiethanolamine (MDEA) solutions and the mass transfer rate can reach up to $9.61 \mathrm{mmol} \mathrm{m}^{-2} \mathrm{~s}^{-1}$. Moreover, the effective human blood oxygenation process is also demonstrated using SAPM circuits. Thus, the reported SAPM provides an alternative gas-liquid exchanging method and the simplified process could be of great benefit to the cost-effectively large-scale $\mathrm{CO}_{2}$ capture or gas exchanging applications.

\section{INTRODUCTION}

Gas adsorption/separation is a common and crucial process in biological and human activities, for example, the blood oxygenation in animal respiration, ${ }^{1}$ photosynthesis of plants, ${ }^{2}$ the respiration of eggs, ${ }^{3}$ the adsorption of carbon dioxide by the ocean, ${ }^{4}$ carbon dioxide and sulphur oxides removal for industrial waste gas, ${ }^{5}$ artificial lung,,${ }^{6,7}$ and etc. The common feature of those activities is the formation of the liquid-gas interfaces facilitating 
direct mass exchanges between those two phases.

The gas is normally forming bubbles under liquid, while gas bubbles can burst and spread rapidly to increase the gas-liquid interface area on the surface of superhydrophobic lotus leaf under water, ${ }^{8,9}$ which is named as underwater superaerophilic..$^{8,10-13}$ Thus, porous superhydrophobic membranes which enable to form a large contact interface are an emerging technology for gas separation and absorption in contact with liquid. Compared to the traditional man-made gas-liquid contactors, such as spray tower, ${ }^{14}$ wet scrubbers, ${ }^{15}$ distillation columns ${ }^{16}$ and falling film wall reactors, ${ }^{17}$ the porous gas-liquid hydrophobic polymer membranes, made from commercial polypropylene and polytetrafluoroethylene etc., ${ }^{18-21}$ possess the unique characteristics of non-dispersive gas-liquid contacts, two independently manipulated phases, higher surface area to volume ratio, smaller volume, modularization, reduced mass transfer resistance and energy saving. ${ }^{22}$ Moreover, with superaerophilic surfaces, gas-liquid-solid interface provides a possibility that the liquid selectively adsorbs the gas from the gas layer between solid and liquid. Many efforts have been devoted to enhancing the hydrophobicity and durability of the porous membranes for efficient gas absorption. The robust superomniphobic membranes have shown a carbon dioxide adsorption rate of $2.5 \mathrm{mmolm}^{-2} \mathrm{~s}^{-1}$ under the premise of MDEA mass fraction of $20 \%$ and pure carbon dioxide. ${ }^{23}$ The fluorocarbon-modified electrospun polydimethylsiloxane (PDMS)/PVDF nanofibrous membranes achieved a $\mathrm{CO}_{2}$ absorption flux of approximately $1.5 \mathrm{mmol} \mathrm{m} \mathrm{m}^{-2} \mathrm{~s}^{-1} \cdot{ }^{24}$ The superhydrophobic ceramic membrane contactor, ${ }^{25}$ whose $\mathrm{CO}_{2}$ removal efficiency and $\mathrm{CO}_{2}$ mass transfer rate maintain above $90 \%$ and $0.06 \mathrm{mmol} \mathrm{m}^{-2} \mathrm{~s}^{-1}$, respectively.

In order to obtain high adsorption efficiency, a high gas or liquid transfer rate is required. 
However, for hydrophobic gas-liquid contact membranes, achieving a high gas transfer rate is still a challenge. Because the superhydrophobic film on the surface of the solid membrane is a porous thin coating, the liquid gas-absorbents can possibly penetrate the hydrophobic pores through the gradually wetted process generating leaking routes, which deteriorates the membrane properties over a long period of time. We noticed that the porous bulk superhydrophobic materials have been used to collecting methane ${ }^{26,27}$ or $\mathrm{H}_{2}$ bubbles ${ }^{28}$ from water through a directional bubble transport in an aqueous environment. ${ }^{29-32}$ Therefore, a porous bulk superhydrophobic material could be possibly fabricated as a more stable gasconductor under liquid for an efficient gas adsorption.

In this work, we present a porous worm-like composite bulk material with superamphiphobicity and superaerophilicity and apply it for efficient under-liquid gas adsorption. The porous superamphiphobic monolith (SAPM) can be cut into strips that are connected to form a free-standing gas-conductive circuit under various aqueous and oily liquids for the adsorption of carbon dioxide and the oxidation of blood. The SAPM circuits can be easily assembled and conveniently control gas flow direction under liquids. A SAPM circuit possesses a high area to volume ratio (4.93), a large flux rate $\left(1200 \mathrm{ml} \mathrm{cm}^{-2} \mathrm{~min}^{-1}\right)$ for $\mathrm{CO}_{2}$ adsorption, excellent corrosion resistance, thermal resistance, and good durability.

\section{EXPERIMENTAL SECTION}

Materials: Methyldiethanolamine (MDEA), hexamethylene (97\%), glycerin, methylene blue, olive oil, $\mathrm{NaOH}$, ammonia solution (25\%-28\%), $\mathrm{HCl}(36 \%-38 \%)$ were obtained from Sino Pharm 
Chemical Reagent Co. Ltd. Hexadecane (98\%), Polyvinylidenefluoride (PVDF), 1H,1H,2H,2Hperfluorodecyltrichlorosilane(PFTS) were purchased from Aladdin. $\mathrm{CO}_{2}$ mixed gas $\left(40 \mathrm{vol} \% \mathrm{CO}_{2}\right.$ and $60 \mathrm{vol} \% \mathrm{~N}_{2}$ ) was obtained from Wuhan Xiangyun Industrial Co. Ltd. Low-temperature expandable graphite (LTEG) (99\%) was purchased from Qindao Tengsheng Da Carbon Machinery Co. Ltd. All reagents were used as received.

Preparation of LTEG/PVDF porous composite materials: PVDF and LTEG (10 $\mathrm{wt} \%$, $12.5 \mathrm{wt} \%, 15 \mathrm{wt} \%, 17.5 \mathrm{wt} \%$, and $20 \mathrm{wt} \%$, the total mass of PVDF and LTEG is $5 \mathrm{~g}$ ) were mixed in an agate grinding pot. The mixture was tableted by a powder pressing machine with an applied pressure of $10 \mathrm{MPa}$ for $5 \mathrm{~min}$. The diameter of the obtained tablet is $60 \mathrm{~mm}$. The tablets were heated at $300{ }^{\circ} \mathrm{C}$ for $10 \mathrm{~min}$ to produce porous LTEG/PVDF composite materials. The LTEG particle sizes are 200 meshes, 100 meshes and 80 meshes and their size expansions after heating are around 40-60 times, 100-160 times and 300-425 times, respectively. The samples are donated as EG-200-15wt\%, EG-100-15wt\% and EG-80$15 \mathrm{wt} \%$, respectively.

Preparation of super-amphiphobic LTEG/PVDF porous monoliths: 1ml PFTS was dropped in $200 \mathrm{ml}$ hexamethylene and then the solution was set aside for $72 \mathrm{~h}$. The porous LTEG/PVDF composite materials were dip-coated in PFTS solution, and then dried in air for $30 \mathrm{~min}$ and placed in a thermostatic blast oven at $60{ }^{\circ} \mathrm{C}$ for $24 \mathrm{~h}$. The obtained superamphiphobic porous monoliths are donated as SAPM-200-15wt $\%$, SAPM-100-15wt $\%$ and SAPM-80-15wt\%, respectively.

Characterization of the super-amphiphobic porous monoliths (SAPM): The morphologies of the materials were examined using scanning electron microscope (SEM, ULTRA PLUS-43-13) and optical microscope (Olympus BX51). The contact angle of various liquids on the SAPM was 
measured by a Contact Angle tester (Theta Lite, Biolin Scientific) in the sessile mode at room temperature. A $6.6 \mathrm{~cm}$ long SAPM was used for carbon dioxide adsorption detection. The entire adsorption detection system is closed with a volume of 3.2 liter. Air is pumped into the internal pipeline, and the gas in the system can be circulated through SAPM. Infrared detection of carbon dioxide in the system can detect the concentration of carbon dioxide in real time.

Airflow rate detection: SAPM is completely submerged in liquids. Air is pumped in from one end of the SAPM, and the rate of intake air is continuously increased until the bubbles start to appear in the middle of the SAPM material, and the air flow reaches the maximum speed at this time.

Water pressure resistance test: a tube with an inner diameter of $0.5 \mathrm{~cm}$ is set on SAPM, and water is continuously added in the tube until the liquid level begins to decrease.

Blood oxygen test: blood was injected from the blood inlet into a gas exchange room and collected from blood outlet. The collected blood at the outlet was injected into the gas exchange room from the inlet again for circulation. Nitrogen or oxygen was pumped from gas inlet into the inside of the hollow super-amphiphobic pipeline. Blood did not leak into the pipeline interior; Partial pressure of oxygen $\left(\mathrm{pO}_{2}\right)$ and oxygen saturation $\left(\mathrm{sO}_{2}\right)$ in blood samples before and after the introduction of oxygen were measured on the blood gas analyzer (Radiometer, Copenhagen, Denmark).

RESULTS AND DISCUSSION 

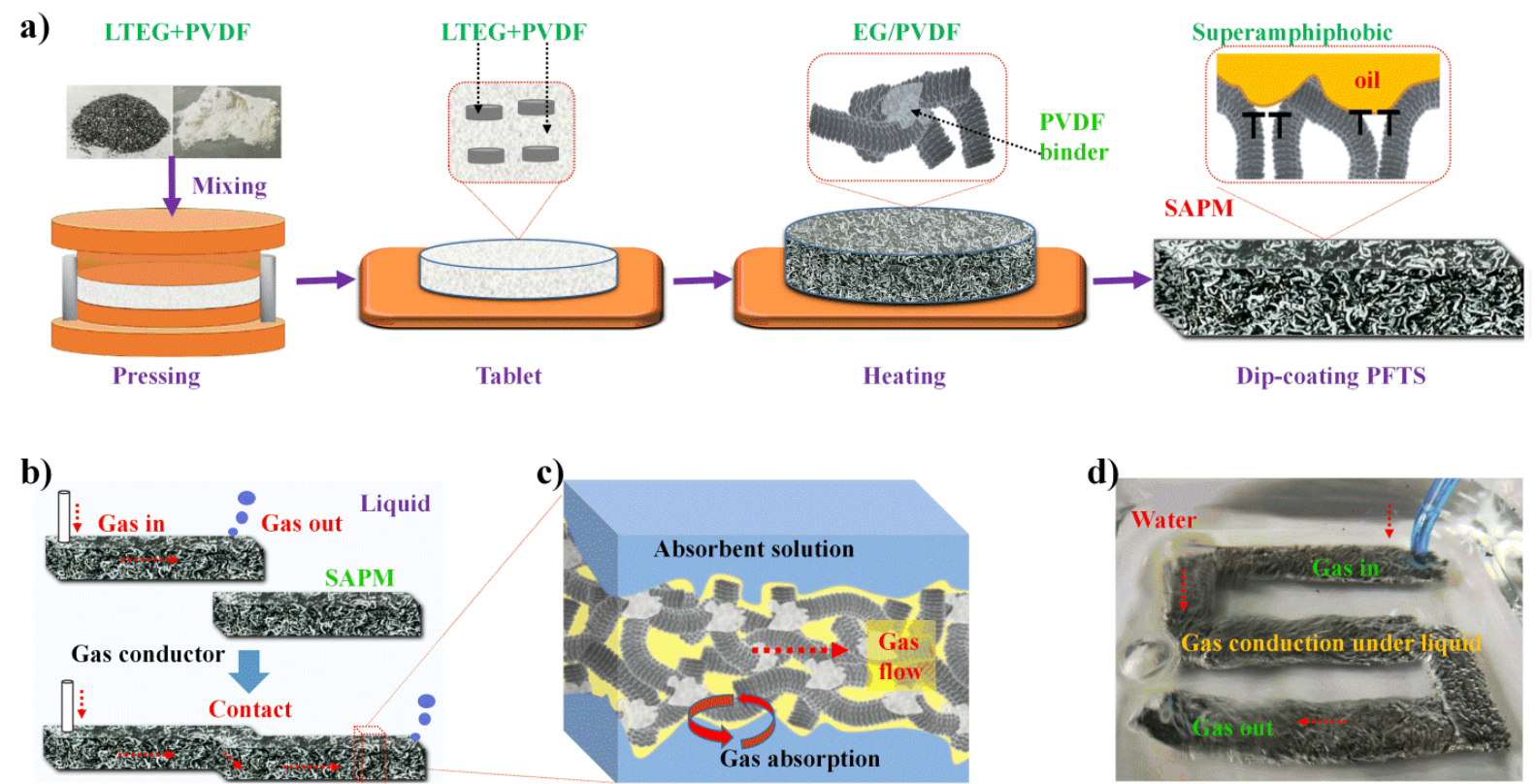

Figure 1. a) Schematic fabrication process of superamphiphobic LTEG/PVDF porous monoliths (SAPM); b) the cartoon of gas-conducting performance with connected SAPM under liquid; c) illustrated gas/liquid exchanging at the superamphiphobic and superaerophilic interface between liquid and gas ; d) A photo of mechanically connected free-standing SAPM circuit for gasconduction under water.

Figure 1a) shows a schematic diagram of the SAPM preparation. LTEG/PVDF composite tablet was heat-treated at $300{ }^{\circ} \mathrm{C}$. It was found almost no weight loss at this heat treatment temperature, indicating that PVDF has no obvious decomposition, which was evidenced by the thermal gravity and differential scanning calorimetry tests (TGA-DSC Figure S1). The porous LTEG/PVDS composite was obtained through the thermal expansion of graphite powder. The low-temperature expanded graphite forms a worm-like skeleton. PVDF acts as a binder to prevent the expanded graphite from pulverization. The block of expanded graphite was cut into strips that were then dip- 
coated in $1 \mathrm{H}, 1 \mathrm{H}, 2 \mathrm{H}, 2 \mathrm{H}$-perfluorodecyltrichlorosilane (PFTS) solution to obtain superamphiphobicity. It was found that the dip-coated strips also show superaerophilicity. ASAPM strip can not only conduct gas but also direct gas flowing (Figure 1b). In Figure 1c, the exchanging or absorption process occurs at the interface of the gas-solid-liquid along the surface of the SAPM. The disordered channel architecture could generate turbulent gas flow, which is beneficial to gas/liquid contact and absorption. A stable gas-liquid contact film can be formed between the gas conductor and the liquid. SAPM has a rough gas-liquid interface which effectively increases the contact area to the superamphiphobic coating.

When two pieces of the strips are in physical contact, the gas flows in from one end of SAPM strip and comes out from one end of the other SAPM strip (Figure 1d). Therefore, SAPM circuits can be built into designed shapes for effectively gas directing and exchanging under liquid. Different gases, such as $\mathrm{O}_{2}, \mathrm{CO}_{2}, \mathrm{H}_{2} \mathrm{~S}$, or organic gases, could flow through the gas conductor. The various liquids can be used, oily or aqueous solutions, such as $0.2 \mathrm{M} \mathrm{NaOH}$ solution, $0.2 \mathrm{M}$ MDEA solution, ammonia solution, $5 \mathrm{wt} \%$ hydrochloric acid solution, glycerin solution, olive oil and etc. (Figure S2 and support video 1-6 for details). 

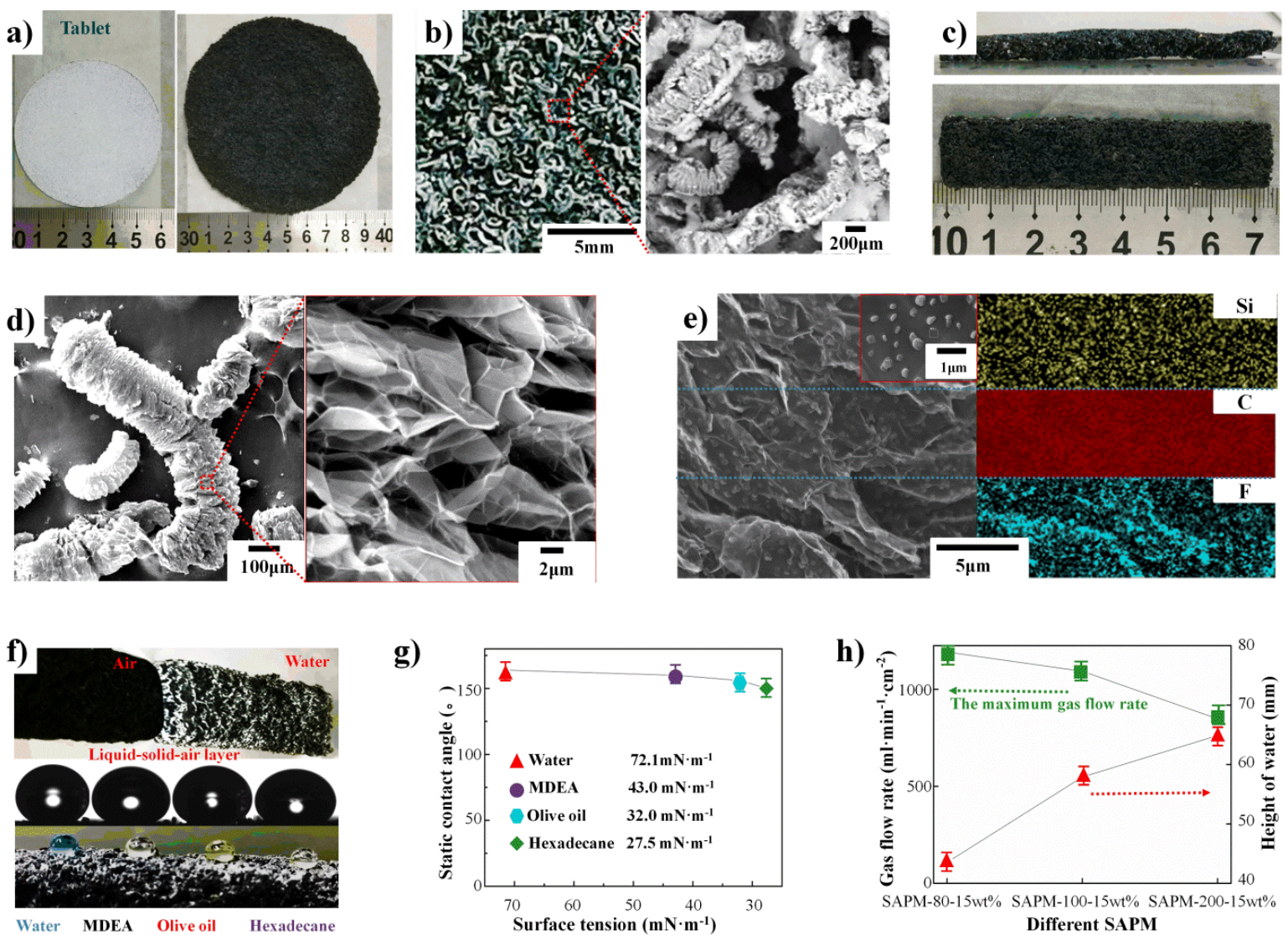

g)

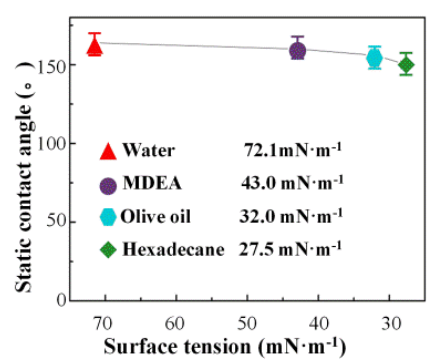

h)

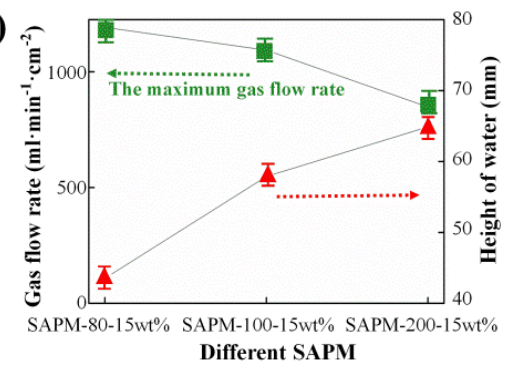

Figure 2. Morphologies and the superamphiphobic properties of SAPM with EG-200. a) The images of pressed mixture tablet of LTEG/PVDF (left) and after heat-treatment (right); b) porous EG-200-15wt\% low (left) and high (right) amplification SEM image; c) EG-200-15wt\% strip image, side view (top), top view (bottom); d) the SEM images of worm-like LTEG powder showing the layered graphene morphology; e) the SEM image and EDS mapping of SAPM. The hydrolyzed 1H,1H,2H,2H-perfluorodecyltrichlorosilane (PFTS) nanoparticles (about $100 \mathrm{~nm}$ ) can be observed, and the fluorine, carbon, silicon EDS mapping which is corresponding to the SEM picture; f) the picture of SAPM in water showing a thin layer of gas surrounding the SAPM surface. Liquid droplets on SAPM (methyl blue added to the water); g) the SCA for different liquids: water, MDEA, olive oil, hexadecane on SAPM; $h$ ) the maximum gas flow rate of SAPM with different 
LTEG in water, and the maximum height of water on different SAPM, which symbolizes the depth of the water.

Three types of expanded graphite powders, named as EG-80, EG-100, and EG-200, respectively, were used to fabricate SAPMs. Their optical and scanning electron micrographs are shown in Figure S3 a, b and c. The left image in Figure 2a is a photo of pressed pellet of PVDF and $15 \mathrm{wt} \%$ EG-200 prior to heat treatment. The initial diameter of the pellet was about $60 \mathrm{~mm}$, and it expanded to $\sim 95 \mathrm{~mm}$ after heat treatment, as shown in the right picture of Figure 2a. If the total mass of LTEG and PVDF remains constant but the ratio varies, as shown in Figure S4, when the mass fraction of LTEG increases, the diameter of the composite expands continuously and almost doubled at $20 \mathrm{wt} \%$ of EG-80. It can be seen from Figure S5 that the expanded volume increases linearly, indicating that bulk density of the expanded graphite block decreases. The volume expansion of EG-200 is the smallest but the bulk density the largest. The largest expansion observed in EG-80 is probably because it has the largest initial graphite particle size dimension (Figure S3).

Figure $2 \mathrm{~b}$ shows two images of a SAPM (left) and its magnified view (right). The worm-like graphites are interconnecting, showing knitting worm-like patterns. Denser network is obtained for SAPM-200-15\% with smaller graphite particles (Figure S6). The worm-like expanded graphite is bound by PVDF (Figure S7). The SAPM is mechanically processable and can be easily cut into strips (Figure 2c). The worm-like EG-200 with a length of about $1000 \mu \mathrm{m}$ and a diameter about $200 \mu \mathrm{m}$ is consisted of many stacked graphene layers with air spacing. The randomly wrinkled morphology could form a hang structure which could be beneficial to oil repelling ${ }^{33}$. After loading of PFTS, the nano-sized particles are located on the layered graphene. The EDS mapping and 
patterns (Figure S8) indicate that the nanoparticles are fluorine rich, suggesting that the nano particles are the hydrolyzed PFTS.

When the SAPM strip is partially immersed in water, as shown in Figure $2 \mathrm{f}$ (top picture), a shining layer at the gas/liquid interface is formed due to the superaerophilic surface of SAPM. The drops of water, MDEA, olive oil and hexadecane stay still on the SAPM surface in Figure $2 \mathrm{f}$ (bottom picture), indicating excellent superamphiphobic properties. Their surface contact angle (SCA) test images are shown in Figure $2 \mathrm{f}$ and $2 \mathrm{~g}$ and the contact angle of water, MDEA, olive oil and hexadecane is $164 \pm 3^{\circ}, 160 \pm 3^{\circ}, 156 \pm 3^{\circ}$ and $150 \pm 3^{\circ}$, respectively. These liquids can form a gas layer on the surface of SAPM and a stable gas pipeline under liquid. Figure $2 \mathrm{~h}$ shows the maximum air flow velocity at a water depth of $3.5 \mathrm{~cm}$ and maximum water pressure resistance of three SAPM materials after complete immersion in water. The testing device of air flow is shown in Figure S9a. The water pressure resistance test is shown in Figure S9b. The height of the water column is the water pressure resistance value of the material. It can be seen from Figure $2 \mathrm{~h}$ that the maximum gas flow resistance of SAPM-80-15wt $\%$, SAPM-100-15wt $\%$, and SAPM-200-15wt $\%$ is sequentially decreased, and the maximum gas flow is $1200 \pm 30 \mathrm{ml} \mathrm{min}^{-1} \mathrm{~cm}^{-2}, 1100 \pm 30 \mathrm{ml} \mathrm{min}^{-1}$ $\mathrm{cm}^{-2}$ and $850 \pm 30 \mathrm{ml} \mathrm{min}{ }^{-1} \mathrm{~cm}^{-2}$, respectively. The gas flow rate increased dramatically with the increase of mass fraction of graphite (Figure S10). The hydraulic pressure resistance varied very little against graphite weight percentage, but was dependent on the type of particle size of graphite powder. The SAPM-200-15wt $\%$ can withstand water depth of about $6.5 \pm 0.3 \mathrm{~cm}$ without water penetrating into the sample. This is because SAPM-200-15wt $\%$ has the smallest degree of expansion, largest bulk density and the smallest diameter of pores. 
a)

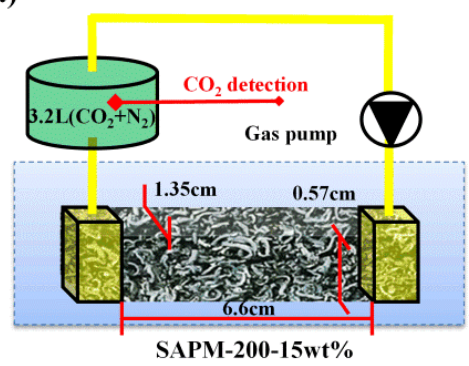

d)

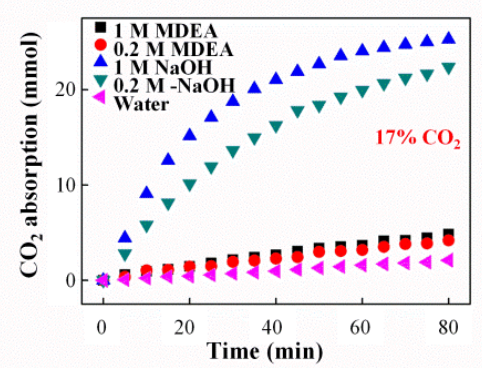

b)

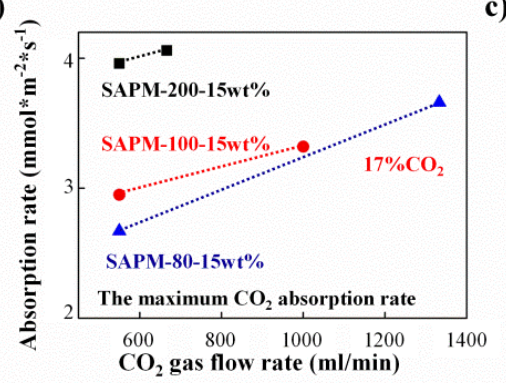

e)

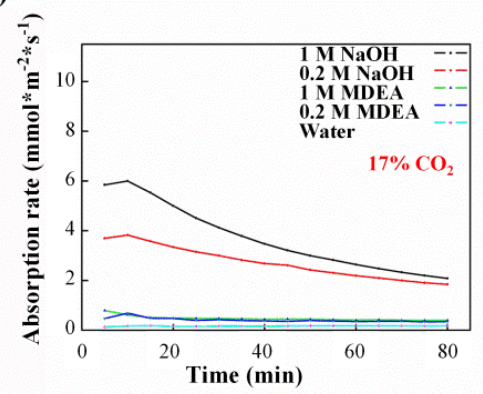

c)

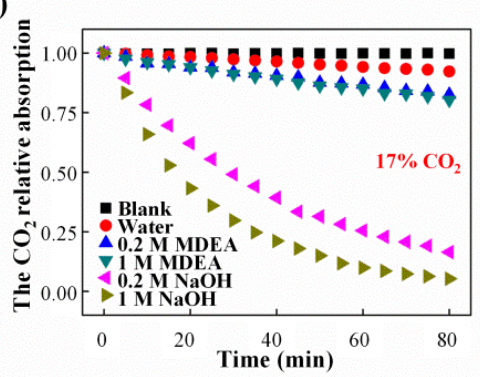

f)

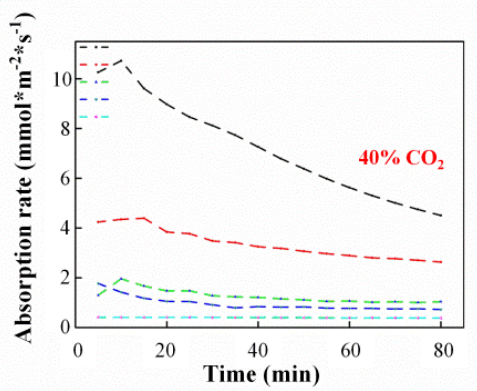

Figure 3. $\mathrm{CO}_{2}$ gas adsorption using SAPM gas conductor circuit. a) the schematic diagram of $\mathrm{CO}_{2}$ captured device by alkaline solution, SAPM-200-15wt\% (length $6.6 \mathrm{~cm}$, width $1.35 \mathrm{~cm}$, height $0.57 \mathrm{~cm}) ; \mathrm{b}$ ) the $\mathrm{CO}_{2}$ absorption rates at different $\mathrm{CO}_{2}$ gas flow rates for SAPM samples; c) the relative absorption of $\mathrm{CO}_{2}$ after 80 mins; d) the amount of $\mathrm{CO}_{2}$ adsorbed after 80 mins. The average $\mathrm{CO}_{2}$ adsorption rate at the corresponding time with the initial concentration of $\mathrm{CO}_{2}$ is $17 \mathrm{vol} \% \mathrm{e}$ ) and the initial concentration of $\mathrm{CO}_{2}$ is $40 \mathrm{vol} \% \mathrm{f}$ ).

The gas adsorption experiment for the as-made SAMP under-liquid circuit was carried out. Figure 3a shows a schematic device for carbon dioxide gas adsorption tests. The total volume of the mixture gas is $3.2 \mathrm{~L}$ with the length of the SAMP monolith being $6.6 \mathrm{~cm}$, the width $1.35 \mathrm{~cm}$, and the height $0.57 \mathrm{~cm}$. The total area of the cuboid is calculated as $25.24 \mathrm{~cm}^{2}$. When the initial $\mathrm{CO}_{2}$ gas concentration is $17 \mathrm{vol} \%$, the gas flow rate $550 \mathrm{ml} \mathrm{min}^{-1}$, and the adsorbent $0.2 \mathrm{M} \mathrm{NaOH}$, the carbon dioxide average adsorption rate of the sample SAPM- $200-15 \mathrm{wt} \%$, SAPM $-100-15 \mathrm{wt} \%$, and 
SAPM- $80-15 \mathrm{wt} \%$ in the first 15 minutes is $3.96 \mathrm{mmol} \mathrm{m}^{-2} \mathrm{~s}^{-1}, 2.95 \mathrm{mmol} \mathrm{m}^{-2} \mathrm{~s}^{-1}$, and $2.67 \mathrm{mmol}$ $\mathrm{m}^{-2} \mathrm{~s}^{-1}$, respectively. SAPM-200-15wt\% has the largest adsorption rate among three samples, which may be attributed to its highest density and the formation of a gas channel under liquid. The higher gas flow resistance to the sample may be beneficial to the collision between gas and liquid at the surface of the monolith, enhancing $\mathrm{CO}_{2}$ mass transfer rate (Figure $3 \mathrm{~b}$ ). Figure $3 \mathrm{c}$ shows the change of the carbon dioxide concentration in the system after gas circulating for $80 \mathrm{~min}$ for different adsorbents using SAPM-200-15wt $\%$. The initial concentration of carbon dioxide was

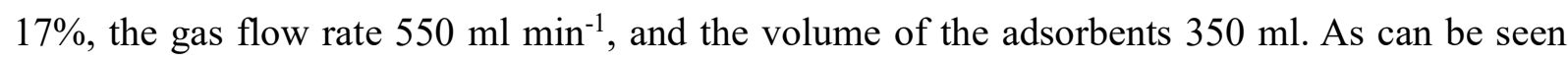
from Figure 3c, without absorbent, the carbon dioxide concentration didn't change within the entire period of circulating time $(80 \mathrm{~min})$, indicating no leakage occurred. However, in the presence of water, 0.2 M MDEA, 1 M MDEA, 0.2 M NaOH, or $1 \mathrm{M} \mathrm{NaOH}$, the concentration of carbon dioxide after gas circulating for $80 \mathrm{~min}$ in the system is reduced by $8 \%, 18 \%, 20 \%, 84 \%, 95 \%$ of the initial concentration, respectively. $\mathrm{CO}_{2}$ is captured in the form of bicarbonate by MDEA according to $\mathrm{CO}_{2}+\left(\mathrm{CH}_{3}\right)\left(\mathrm{CH}_{2} \mathrm{CH}_{2} \mathrm{OH}\right)_{2} \mathrm{~N}+\mathrm{H}_{2} \mathrm{O} \rightarrow\left(\mathrm{CH}_{3}\right)\left(\mathrm{CH}_{2} \mathrm{CH}_{2} \mathrm{OH}\right)_{2} \mathrm{NH}^{+}+\mathrm{HCO}_{3}{ }^{-}$, and by $\mathrm{NaOH}$ according to $2 \mathrm{NaOH}+\mathrm{CO}_{2} \rightarrow \mathrm{Na}_{2} \mathrm{CO}_{3}+\mathrm{H}_{2} \mathrm{O}$. The concentration of carbon dioxide in the system reduces exponentially in the presence of $0.2 \mathrm{M} \mathrm{NaOH}$ and $1 \mathrm{M} \mathrm{NaOH}$. Figure $3 \mathrm{~d}$ shows the number of moles of carbon dioxide adsorbed with different adsorbents for $80 \mathrm{~min}$. After 80 min, the amount of carbon dioxide adsorbed was $2.09 \mathrm{mmol}, 4.2 \mathrm{mmol}, 4.84 \mathrm{mmol}, 22.37 \mathrm{mmol}$ and 25.27 mmol for water, 0.2 M MDEA, $1 \mathrm{M}$ MDEA, 0.2 M NaOH, and 1M NaOH, respectively. The absorption results suggest that SAPM circuits are very effective in gas adsorption, considering small $\left(6.6 \mathrm{~cm}^{*} 1.35 \mathrm{~cm} * 0.57 \mathrm{~cm}\right)$ piece of gas-liquid contact media.

Figure $3 \mathrm{e}$ and $\mathrm{f}$ show the change of the $\mathrm{CO}_{2}$ average adsorption rates against time for different starting concentrations. The test conditions kept the same as above. It can be seen from Figure $3 \mathrm{e}$ 
and $\mathrm{f}$ that when the initial concentration of carbon dioxide is $17 \%$, the average $\mathrm{CO}_{2}$ adsorption rates in the first $15 \mathrm{~min}$ were $0.18,0.48,0.50,3.96$, and $5.50 \mathrm{mmol} \mathrm{m}^{-2} \mathrm{~s}^{-1}$ for pure water, $0.2 \mathrm{M}$ MDEA, $1 \mathrm{M}$ MDEA, $0.2 \mathrm{M} \mathrm{NaOH}$, and $1 \mathrm{M} \mathrm{NaOH}$ solution, respectively. As the initial $\mathrm{CO}_{2}$ concentration increases, the rate of carbon dioxide adsorption increases. When the initial $\mathrm{CO}_{2}$ concentration increased to $40 \mathrm{vol} \%$, the average adsorption rates of $\mathrm{CO}_{2}$ increased rapidly in the first $15 \mathrm{~min}$ to a value of $9.61,4.39,1.67,1.17,0.40 \mathrm{mmol} \mathrm{m}^{-2} \mathrm{~s}^{-1}$ for $1 \mathrm{MNaOH}, 0.2 \mathrm{M} \mathrm{NaOH}, 1 \mathrm{M}$ MDEA, 0.2M MDEA and pure water solution, respectively. And when the initial $\mathrm{CO}_{2}$ concentration increased to $100 \mathrm{vol} \%$, the average adsorption rates of $\mathrm{CO}_{2}$ in the first $15 \mathrm{~min}$ is 2.78 mmol m $\mathrm{m}^{-2} \mathrm{~s}^{-1}$ for 1M MDEA (See the Figure S11). The SAPM total volume is $5.07 \mathrm{~cm}^{3}$, and its area to volume ratio is 4.93 .

a)

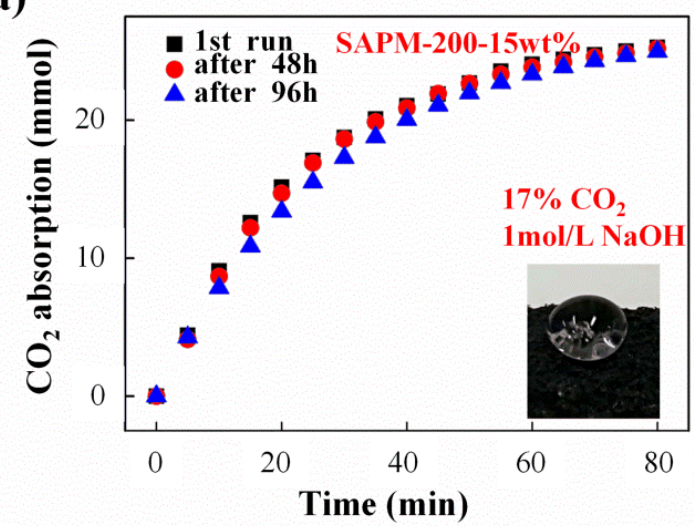

b)

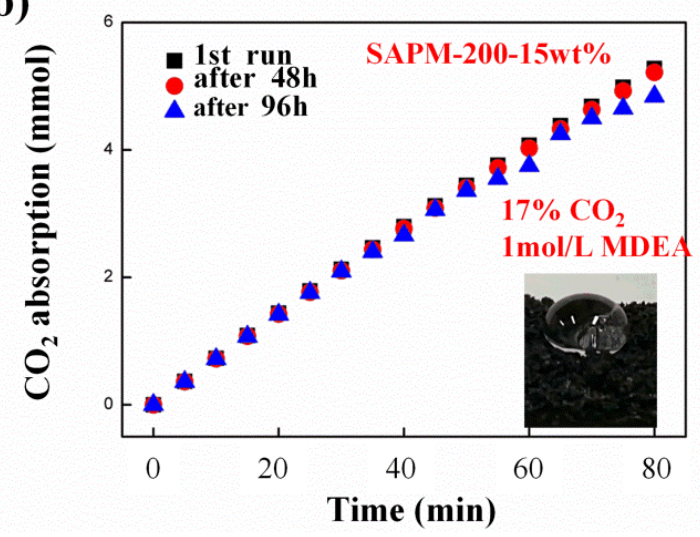

Figure 4. The operation stability of SAPM gas conduction circuits for $\mathrm{CO}_{2}$ adsorption. a) $\mathrm{NaOH}$ $(1 \mathrm{M})$ and b) MDEA (1M) solution was exchanged during the operation every 48 hours. The inserted images are water and MDEA drops on the SAPM after $96 \mathrm{~h}$ for a) and b) respectively.

To investigate the long-term performance of the SAPM circuit as the gas-liquid contactor, we 
carried out a repeatable test for the device by replacing the $\mathrm{NaOH}$ and MDEA solutions every 48 h. It can be seen in Figure 4a and $b$ that after soaking for $96 \mathrm{~h}$, the $\mathrm{CO}_{2}$ adsorption for SAPM-200$15 \mathrm{wt} \%$ shows a slight decrease during the whole test. After the test, no serious wetting was observed on the surface of the sample, indicating well preserved superamphiphobic properties. The inner walls of SAPM pores also maintain a stable gas flow. When the sample was dried at 80 ${ }^{\circ} \mathrm{C}$ for $30 \mathrm{~min}$, the performance can be completely recovered. This suggests that the SAPMs possess high durability even in contact with the high concentration alkaline solution.

a)

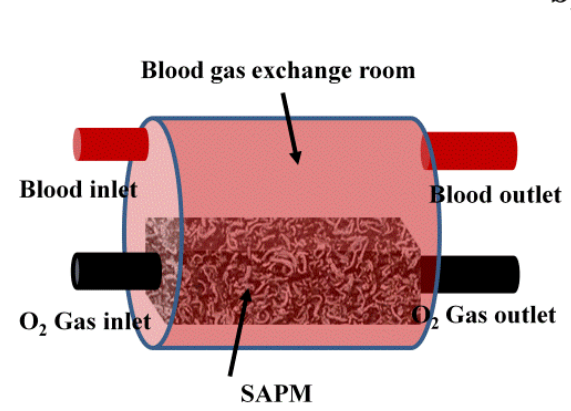

b)

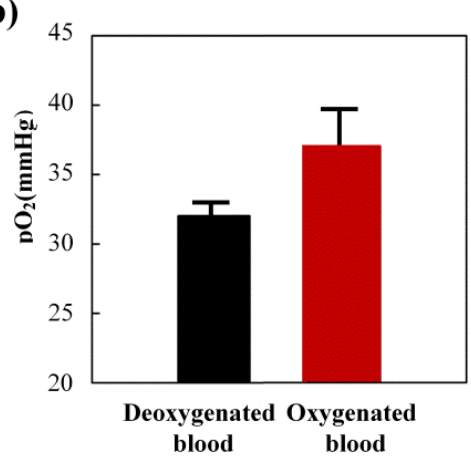

c)

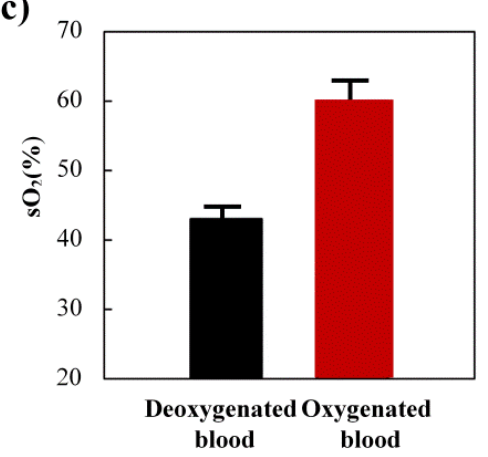

Figure 5. a) Scheme of the blood oxygenation operation; b) partial pressure of oxygen $\left(\mathrm{pO}_{2}\right)$ measured before and after oxygen was introduced. $\mathrm{pO}_{2}$ elevated for $5 \mathrm{mmHg}$ from $32 \mathrm{mmHg}$ to $37 \mathrm{mmHg}$ after oxygen was pumped into the device; c) Oxygen saturation $\left(\mathrm{sO}_{2}\right)$ measured before and after oxygen was introduced. $\mathrm{sO}_{2}$ in blood samples significantly increased from $43 \%$ to approximately $60 \%$ after oxygen was pumped into the device, indicative of a successful oxygenation procedure.

Extracorporeal membrane oxygenation (ECMO) with blood oxygenator is used to test the cardiopulmonary function of the patient that is severely impaired. As an important component of the oxygenator, gas-liquid membrane contactor is strictly selected to prevent direct oxygen-blood 
contact in case of hemolysis and platelet reduction. Currently, gas permeability and exchange capacity of oxygenator membrane still remain to be improved. To further exhibit the potential application of SAMP circuit, Figure 5a demonstrates the blood gas exchange tasks. Venous whole blood samples donated by a healthy adult were anticoagulated with heparin sodium and were injected into the blood distribution area of the device; outside the superamphiphobic strip, blood was circulated continuously at a flow rate of $10 \mathrm{ml} / \mathrm{min}$. We first pumped nitrogen through the superamphiphobic pipeline interior for $10 \mathrm{~min}$ to deoxygenize blood samples before oxygen was supplied for another 5 min with a gas velocity of $200 \mathrm{ml} \mathrm{min}^{-1}$.

The partial pressure of oxygen $\left(\mathrm{pO}_{2}\right)$ and oxygen saturation $\left(\mathrm{sO}_{2}\right)$ were analyzed, which reflected the oxygen dissolved and the percentage of oxygen-combined hemoglobin in the blood. As shown in Figure 5b, $\mathrm{pO}_{2}$ in blood samples was slightly elevated for $5 \mathrm{mmHg}$ from $32 \mathrm{mmHg}$ to $37 \mathrm{mmHg}$ after oxygen was pumped. Interestingly, the introduction of oxygen through the inside of the tube caused a significant increase of $\mathrm{sO}_{2}$ in blood samples from $43 \%$ to approximately $60 \%$ (Figure $5 \mathrm{c}$ ), indicative of a successful oxygenation and an efficient gas exchange procedure. Besides, no blood leakage into the superamphiphobic tube, no clot formation and no hemolysis occurred. We found that gas could efficiently exchange through our superamphiphobic membrane, thus successfully oxygenating the blood, with $\mathrm{pO}_{2}$ and $\mathrm{sO}_{2}$ in blood increasing.

\section{CONCLUSIONS}

In this work, the superamphiphobic porous monoliths (SAPM) are prepared for an effective underliquid gas adsorption. The SAPM is easily prepared with low temperature expandable graphite (LTEG) and polyvinylidenefluoride (PVDF). The worm-like porous architecture and layered hang structure are contributed to the superamphiphobicity and durability. The SAPM strips can be 
constructed into gas-conductive circuits under liquid for gas adsorption in various liquid. We achieved a $\mathrm{CO}_{2}$ adsorption capacity up to $9.61 \mathrm{mmol} \mathrm{m}^{-2} \mathrm{~s}^{-1}$ and the maximum airflow speed through the circuit can reach to $1200 \mathrm{ml} \mathrm{cm}^{-2} \mathrm{~min}^{-1}$. Moreover, the effective human blood oxygenation process is also demonstrated using SAPM. In $5 \mathrm{~min}$, the oxygen saturation increased from $43 \%$ to $60 \%$. Therefore, the SAPM gas-conductive circuit reported here provides a novel gas-liquid exchanging method and the simplified process could be of benefit to the cost-effective large-scale $\mathrm{CO}_{2}$ capture, gas exchanging and etc.

\section{ASSOCIATED CONTENT}

Supporting Information: See the supporting information files on line

\section{AUTHOR INFORMATION}

*Corresponding author, email: jie.zhong@,whut.edu.cn (Jie Zhong); q.zhang@cranfield.ac.uk (Qi Zhang)

\section{Author Contributions}

$\ddagger$ All the authors contributed equally.

\section{Funding Sources}

National Natural Science Foundation of China (NSFC 51672202, 51702243), Hubei Provincial Natural Science Foundation of China (2016CFB464), the Technological Innovation Key Project of Hubei Province (2016AAA041), National College Students Innovation and Entrepreneurship Training Program (20181049701028), the Guangxi Natural Science Foundation (Grants 2016GXNSFCB380006, 2017GXNSFFA198015), the Hubei Provincial Natural Science Foundation of China (Grant No.2018CFA029). 


\section{ACKNOWLEDGMENT}

This work is financially supported by National Natural Science Foundation of China (NSFC 51672202, 51702243), Hubei Provincial Natural Science Foundation of China (2016CFB464), the Technological Innovation Key Project of Hubei Province (2016AAA041), National College Students Innovation and Entrepreneurship Training Program (20181049701028), the Guangxi Natural Science Foundation (Grants 2016GXNSFCB380006, 2017GXNSFFA198015), the Hubei Provincial Natural Science Foundation of China (Grant No.2018CFA029). JZ thanks the support the "Chutian Scholar Program" of Hubei Province, China.

\section{ABBREVIATIONS}

SAPM, superamphiphobic monoliths; LTEG, low temperature expandable graphite ; PVDF, polyvinylidenefluoride; MDEA, methyldiethanolamine; PDMS, polydimethylsiloxane; PFTS, 1H,1H,2H,2H-perfluorodecyltrichlorosilane; SEM, scanning electron microscope; EMCO, Extracorporeal membrane oxygenation.

\section{REFERENCES}

(1) Wagner, W. R.; Griffith, B. P. Reconstructing the Lung. Science 2010, 329, 520-522.

(2) Rumberg, B.; Mueller, A.; Witt, H. T. New Results about the Mechanism of Photosynthesis. Nature 1962, 194, 854-856.

(3) Hinton, H. E. Plastron Respiration in the Eggs of Drosophila and other Flies. Nature 1959, $184,280-281$.

(4) Goldman, J. C.; Dennett, M. R. Carbon Dioxide Exchange between Air and Seawater: no Evidence for Rate Catalysis. Science 1983, 220, 199-201. 
(5) Wang, M. H.; Joel, A. S.; Ramshaw, C.; Eimer, D.; Musa, N. M. Process Intensification for Post-combustion $\mathrm{CO}_{2}$ Capture with Chemical Absorption: A Critical Review. Appl. Energy 2015, 158, 275-291.

(6) Potkay, J. A. The Promise of Microfluidic Artificial Lungs. Lab. Chip.2014, 14(21), 41224138.

(7) Paven, M.; Papadopoulos, P.; Schottler, S.; Deng, X.; Mailaender, V.; Vollmer, D.; Butt, H. J. Super Liquid-repellent Gas Membranes for Carbon Dioxide Capture and Heart-lung Machines. Nat. Commun. 2013, 4, 2512-2518.

(8) Su, B.; Tian, Y.; Jiang, L. Bioinspired Interfaces with Superwettability: from Materials to Chemistry. J. Am. Chem. Soc. 2016, 138(6), 1727-1748.

(9) Wang, J. W.; Zheng, Y. M.; Nie, F. Q.; Zhai, J.; Jiang, L. Air Bubble Bursting Effect of Lotus Leaf. Langmuir 2009, 25(24), 14129-14134.

(10) Yong, J. L.; Chen, F.; Li, M. J.; Yang, Q.; Fang, Y.; Huo, J. L.; Hou, X. Remarkably Simple Achievement of Superhydrophobicity, Superhydrophilicity, Underwater Superoleophobicity, Underwater Superoleophilicity, Underwater Superaerophobicity, and Underwater Superaerophilicity on Femtosecond Laser Ablated PDMS Surfaces. J. Mater. Chem. A 2017, $5(48), 25249-25257$.

(11) Yu, C. M.; Zhang, P. P.; Wang, J. M.; Jiang, L. Superwettability of Gas Bubbles and Its Application: from Bioinspiration to Advanced Materials. Adv. Mater. 2017, 29(45), $1703053-$ 1703066.

(12) Cao, M. Y.; Li, Z.; Ma, H. Y.; Geng, H.; Yu, C. M; Jiang, L. Is Superhydrophobicity Equal to Underwater Superaerophilicity: Regulating the Gas Behavior on Superaerophilic Surface via Hydrophilic Defects? ACS Appl. Mater. Interfaces 2018, 10(24), 20995-21000. 
(13) Pei, C. T.; Peng, Y.; Zhang, Y.; Tian, D. L.; Liu, K. S.; Jiang, L. An Integrated Janus Mesh: Underwater Bubble Anti-buoyancy Unidirectional Penetration. Acs Nano 2018, 12(6), 54895494.

(14) Wu, X. M.; Qin, Z.; Yu, Y. S.; Zhang, Z. X. Experimental and Numerical Study on $\mathrm{CO}_{2}$ Absorption Mass Transfer Enhancement for a Diameter-varying Spray Tower. Appl. Energy 2018, 225, 367-379.

(15) Chen, T. W.; Chu, H. Removal of $\mathrm{SO}_{2}$ and $\mathrm{NO}$ from Flue Gas by Wet Scrubbing Using an Aqueous $\mathrm{NaClO}_{2}$ Solution. J. Hazard. Mater. 2000, 80(1-3), 43-57.

(16) Lu, W. G.; Sculley, J. P.; Yuan, D. Q.; Krishna, R.; Wei, Z. W.; Zhou, H. C. Polyamine Tethered Porous Polymer Networks for Carbon Dioxide Capture From Flue Gas. Angew. Chem. In. Ed. 2012, 51(30), 7480-7484.

(17) Faungnawakij, K.; Sano, N.; Yamamoto, D.; Kanki, T.; Charinpanitkul, T.; Tanthapanichakoon, W. Removal of Acetaldehyde in Air Using a Wetted-wall Corona Discharge Reactor. Chem. Eng. J. 2004, 103(1-3), 115-122.

(18) El-Bourawi, M. S.; Ding, Z.; Ma, R.; Khayet, M. A Framework for Better Understanding Membrane Distillation Separation Process. J. Membr. Sci. 2006, 285(1-2), 4-29.

(19) Wang, Z. H.; Wang, C. Y.; Chen, K. S. Two-phase Flow and Transport in the Air Cathode of Proton Exchange Membrane Fuel Cells. J. Power Sources 2001, 94(1), 40-50.

(20) Davis, M. E. Ordered Porous Materials for Emerging Applications. Nature 2002, 417(6891), 813-821.

(21) Iwasaki, Y.; Uchiyama, S.; Kurita, K.; Morimoto, N.; Nakabayashi, N. A Nonthrombogenic Gas-permeable Membrane Composed of a Phospholipid Polymer Skin Film Adhered to a Polyethylene Porous Membrane. Biomaterials 2002, 23(16), 3421-3427. 
(22) Ozturk, B.; Hughes, R. Evaluation of Mass Transfer Characteristics of Non-porous and Microporous Membrane Contactors for the Removal of $\mathrm{CO}_{2}$. Chem. Eng. J. 2012, 195, 122-131. (23) Geyer, F.; Schönecker, C.; Butt, H. J.; Vollmer, D. Enhancing $\mathrm{CO}_{2}$ Capture Using Robust Superomniphobic Membranes. Adv. Mater. 2017, 29(5), 1603524.

(24) Lin, Y. F.; Ye, Q.; Hsu, S. H.; Chung, T. W. Reusable Fluorocarbon-modified Electrospun PDMS/PVDF Nanofibrous Membranes with Excellent $\mathrm{CO}_{2}$ Absorption Performance. Chem. Eng. J. 2016, 284, 888-895.

(25) Yu, X. H.; An, L.; Yang, J.; Tu, S. T.; Yan, J. Y. $\mathrm{CO}_{2}$ Capture Using a Superhydrophobic Ceramic Membrane Contactor. J. Membr. Sci. 2015, 496, 1-12.

(26) Chen, X.; Wu, Y. C.; Su, B.; Wang, J. M.; Song, Y. L.; Jiang, L. Terminating Marine Methane Bubbles by Superhydrophobic Sponges. Adv. Mater. 2012, 24(43), 5884-5889.

(27) Yong, J. L.; Chen, F.; Huo, J. L.; Fang, Y.; Yang, Q.; Zhang, J. Z.; Hou, X. Femtosecond Laser Induced Underwater Superaerophilic and Superaerophobic PDMS Sheets with through Microholes for Selective Passage of Air Bubbles and Further Collection of Underwater Gas. Nanoscale 2018; 10(8): 3688-96.

(28) Yu, C. M.; Cao, M. Y.; Dong, Z. C.; Li, K.; Yu, C. L.; Wang, J. M.; Jiang, L. Aerophilic Electrode with Cone Shape for Continuous Generation and Efficient Collection of $\mathrm{H}_{2}$ Bubbles. Adv. Funct. Mater. 2016, 26(37), 6830-6835.

(29) Yu, C. M.; Zhu, X. B.; Cao, M. Y.; Yu, C. L.; Li, K.; Jiang, L. Superhydrophobic Helix: Controllable and Directional Bubble Transport in an Aqueous Environment. J. Mater. Chem. A 2016, 4(43), 16865-16870. 
(30) Duan, J. A.; Dong, X. R.; Yin, K.; Yang, S.; Chu, D. K. A Hierarchical Superaerophilic Cone: Robust Spontaneous and Directional Transport of Gas Bubbles. Appl. Phys. Lett. 2018, 113(20), 203704-203705.

(31) Ma, H. Y.; Cao, M. Y.; Zhang, C. H.; Bei, Z. L.; Li, K.; Yu, C. M.; Jiang, L. Directional and Continuous Transport of Gas Bubbles on Superaerophilic Geometry-Gradient Surfaces in Aqueous Environments. Adv. Funct. Mater. 2018, 28(7), 1705091.

(32) Tian, P.; Gao, X. Y.; Wen, G.; Zhong, L. S.; Wang, Z. L. L.; Guo, Z. G. Diving-floating Locomotion Induced by Capturing and Manipulating Bubbles in an Aqueous Environment. Chem. Commun. 2018, 54(83), 11713-11716.

(33) Tuteja, A.; Choi, W.; Ma, M. L.; Mabry, J. M.; Mazzella, S. A.; Rutledge, G. C.; McKinley, G. H.; Cohen, R. E. Designing Superoleophobic Surfaces. Science 2007, 318(5856), 1618-1622.

BRIEFS.

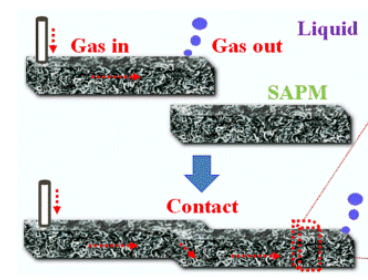

Gas conductor under liquids

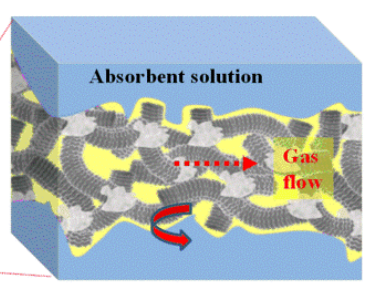

Gas absorption

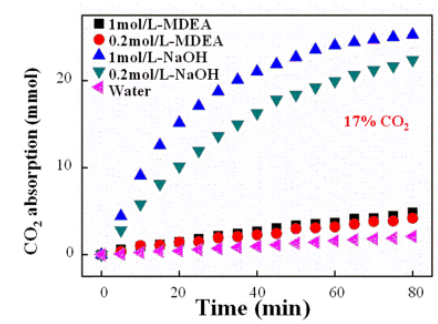

TOC: The superamphiphobic porous material can be used as a gas conductive circuit under liquid and as gas adsorption and separation. 
2019-06-14

Efficient gas adsorption using

superamphiphobic porous monoliths as

the under-liquid gas-conductive circuits

Wen, Min

American Chemical Society

Wen M, Peng C, Yao M, et al., (2019). Efficient gas adsorption using superamphiphobic porous monoliths as the under-liquid gas-conductive circuits. ACS Applied Materials and Interfaces,

Volume 11, Issue 27, pp. 24795-24801

https://doi.org/10.1021/acsami.9b07510

Downloaded from Cranfield Library Services E-Repository 